\title{
The Gerbil Elevated Plus-maze II: Anxiolytic-like Effects of Selective Neurokinin NK1 Receptor Antagonists
}

Geoffrey B. Varty, Ph.D., Mary E. Cohen-Williams, B.Sc., Cynthia A. Morgan, B.Sc., Ursula Pylak, M.S., Ruth A. Duffy, Ph.D., Jean E. Lachowicz, Ph.D., Galen J. Carey, Ph.D., and Vicki L. Coffin, Ph.D.

Neurokinin NK1 receptor antagonists may have therapeutic potential in the treatment of anxiety and depression. Species variants in the NK1 receptor result in reduced affinity of NK1 receptor antagonists at rat and mouse NK1 receptors, making it difficult to test NK1 antagonists in traditional preclinical models of anxiety and depression. Gerbil NK1 receptors are similar in homology to the human NK1 receptor. In a companion article, we described the anxiety-like behavioral profile of gerbils on an adapted elevated plus-maze, and the ability of anxiolytic drugs to produce anti-anxiety effects in the gerbil elevated plus-maze. The aim of the present study was to determine whether oral (p.o.) administration of the NK1 receptor antagonists MK-869, L-742,694,

L-733,060, CP-99,994, and CP-122,721 produced anxiolyticlike effects in the gerbil elevated plus-maze. Upon testing, all five NK1 antagonists produced anxiolytic-like effects. MK$869(0.01-3 \mathrm{mg} / \mathrm{kg})$ was the most potent NK1 antagonist, producing anxiolytic-like effects on percentage of open arm time, percentage of open arm entries, stretch-attend postures, and head dips at 0.03-0.3 mg/kg doses. L-742,694 (1-30 mg/ $\mathrm{kg}$ ) and $\mathrm{L}-733,060(1-10 \mathrm{mg} / \mathrm{kg})$ produced anxiolytic-like effects on percentage of open arm time and stretch-attend postures at 3-10 $\mathrm{mg} / \mathrm{kg}$ doses. CP-99,994 (3-30 $\mathrm{mg} / \mathrm{kg}$ ) only produced an anxiolytic-like effect on stretch-attend postures. CP-122,721 (3-30 mg/kg) produced an anxiolytic-like effect on percentage of open arm time at $30 \mathrm{mg} / \mathrm{kg}$. The order of potency of the NK1 antagonists to increase percentage of open arm time was very similar to their potency to block NK1 agonist-induced foot-tapping. These studies demonstrate that neurokinin NK1 receptor antagonists produce anxiolytic-like effects in a novel gerbil elevated plus-maze, and suggest that this is an appropriate model to test NK1 antagonists for preclinical anxiolytic activity.

[Neuropsychopharmacology 27:371-379, 2002] (C) 2002 American College of Neuropsychopharmacology. Published by Elsevier Science Inc.
KEY WORDS: Anxiety; Elevated plus-maze; Gerbil; Tachykinin; Neurokinin NK1 receptor; NK1 receptor antagonists

From the CNS Biological Research, Schering-Plough Research Institute, 2015 Galloping Hill Road, Kenilworth, NJ 07033, USA.

Address correspondence to: Geoffrey Varty, Ph.D., K-15-2-2600 CNS/CV Biological Research, Schering-Plough Research Institute, 2015 Galloping Hill Road, Kenilworth, NJ 07033. Tel: (908) 740-3409; Fax: (908) 740-3294; E-mail: Geoffrey.Varty@SPCorp.com

Received August 3, 2001; revised November 6, 2001; accepted February 8, 2002.

Online publication: 2/22/02 at www.acnp.org/citations/ Npp022202249-2.
The tachykinin system, particularly the neurokinin NK1 receptor, may represent a new target for the treatment of a number of psychiatric disorders. Of greatest significance to the field, Kramer et al. (1998) described the anxiolytic and antidepressant effects of the NK1 antagonist, MK-869, in a 6-week clinical trial in patients diagnosed with co-morbid anxiety and depression. In the few studies that have assessed the anxiolytic-like and antidepressant-like effects of NK1 receptor antagonists in preclinical tests, results support the hypotheses that NK1 receptor blockade may have a role in the treatment of affective disorders. For example, the NK1 an- 
tagonists, FK-888 and WIN51,708, were shown to have anxiolytic-like effects in the mouse and rat elevated plus-mazes, respectively (Teixeira et al. 1996; Nikolaus et al. 1999). Further, some recent publications have described the anxiolytic-like effects of the NK1 antagonist, NKP-608, in the rat social interaction assay (File 2000; Vassout et al. 2000), and the antidepressant effects of NKP-608 in the rat chronic mild stress paradigm (Papp et al. 2000).

Interestingly, WIN51,708, FK-888, and NKP-608 are three of a small number of non-peptide NK1 receptor antagonists that have comparable affinity at the rat and human NK1 receptors. Due to species variants in the NK1 receptor (see Pradier et al. 1995), the majority of NK1 antagonists are significantly less potent at rat and mouse NK1 receptors, compared with human NK1 receptors (Beresford et al. 1991; Gitter et al. 1991; McLean et al. 1993; Saria 1999). Therefore, it is difficult to assess the effects of many NK1 antagonists in traditional rat and mouse models of anxiety. In contrast to rats and mice, NK1 receptors in guinea pigs and gerbils are closer in homology to the human NK1 receptor. Furthermore, NK1 antagonists bind with similar affinity to gerbil, guinea pig, and human NK1 receptors (Beresford et al. 1991; Gitter et al. 1991). In guinea pigs, a pharmacologically validated behavioral model of acute separation stress has been described. Specifically, maternal separation of guinea pig pups produces intense audible vocalizations that are reduced by standard anxiolytic drugs such as diazepam, and antidepressant drugs such as fluoxetine (Molewijk et al. 1996). Based on this, Kramer et al. (1998) used this behavioral assay to test the anxiolytic-like/antidepressant-like effects of the NK1 antagonists MK-869 and L-733,060, both of which have reduced affinity at the rat and mouse NK1 receptors. Both of these NK1 antagonists reduced the number of vocalizations with similar efficacy to fluoxetine and diazepam.

In the NK1 research field, gerbils have most frequently been used in a pharmacodynamic assay to assess how well NK1 antagonists penetrate the CNS following peripheral administration. Briefly, pretreatment with CNS penetrant NK1 antagonists blocks the rhythmic hind foot-tapping produced when the selective NK1 receptor agonist, GR-73632 (Hagan et al. 1991), is administered into the CNS via intracerebroventricular (icv) injection (Bristow and Young 1994; Rupniak and Williams 1994; Rupniak et al. 1997).

There are few reports, however, describing the behavior of gerbils in traditional in-vivo models of anxiety. In recent publications that adapted rat anxiety models for gerbils, Sandra File and colleagues described the anxiolytic-like effects of diazepam and the NK1 antagonist L-760,735 in the gerbil social interaction test (File et al. 2001; Cheeta et al. 2001), while Ballard et al. (2001) described the anxiolytic-like effects of diaz- epam and the NK1 antagonists MK-869 and CP-99,994 in a fear-conditioning paradigm. To expand on these findings, and based on the success of the rat and mouse elevated plus-mazes, we recently described the characterization and pharmacological validation of the gerbil elevated plus-maze as a model to screen anxiolytic compounds (Varty et al. 2002). Briefly, using an elevated plus-maze designed specially for the gerbil, we demonstrated that gerbils displayed a behavioral profile that was suitable for testing anxiolytic drugs. Indeed, standard anxiolytic drugs including diazepam and buspirone, as well as tricyclic and SSRI antidepressant drugs produced acute anxiolytic-like effects in the gerbil elevated plus-maze.

The aim of the present studies was to confirm that NK1 antagonists exhibit preclinical anxiolytic-like activity using a traditional anxiety model adapted for the gerbil. To this end, five selective NK1 antagonists, namely MK-869, L-742,694, L-733,060, CP-99,994, and CP-122,721, were tested in the gerbil elevated plusmaze. These antagonists are representative of compounds that have been described in the NK1 preclinical and clinical literature (McLean et al. 1993; Rupniak and Williams 1994; McLean et al. 1996; Rupniak et al. 1997; Kramer et al. 1998). Specifically, we first assayed the receptor binding profile of these five NK1 antagonists at gerbil, rat, and human NK1 receptors, to confirm that these NK1 antagonists have reduced affinity at rat NK1 receptors. The NK1 antagonists were then tested in the gerbil NK1 agonist-induced foot-tapping assay following oral administration to established orally active doses. Finally, the compounds were tested in the gerbil elevated plus-maze paradigm and their potency in this behavioral assay was compared with their ability to inhibit foot-tapping behavior.

\section{MATERIALS AND METHODS}

\section{In-vitro NK1 Binding Studies}

Chinese hamster ovary $(\mathrm{CHO})$ cells expressing the human NK1 receptor were obtained from Professor James Krause (Washington University School of Medicine, St. Louis, MO). Rat and gerbil striatal tissues were obtained from the brains of animals sacrificed under $\mathrm{CO}_{2}$ anesthesia. Membrane fractions from both rat and gerbil tissues, and $\mathrm{CHO}$ cells, were prepared by homogenizing in $50 \mathrm{mM}$ Tris $\mathrm{HCl}$ buffer ( $\mathrm{pH}$ 7.4) followed by centrifugation at $40,000 \times \mathrm{g}$ for $30 \mathrm{~min}$. The pellet was then re-suspended in the same buffer and the protein concentration determined using the BCA reagent kit (Pierce, Rockford, IL, USA). After a second centrifugation (conditions as above), the pellet was re-suspended in buffer containing protease inhibitors (Roche Biochemicals, Indianapolis, IN, USA) and stored at $-80^{\circ} \mathrm{C}$ until use. 
Binding studies were based on the methods of Cascieri et al. (1985). Competition binding assays were performed in 96-well plate format by incubating membranes (4-20 $\mu$ g pro.) with Bolton Hunter labeled ${ }^{125} \mathrm{I}-$ Substance P ( $\left.{ }^{125} \mathrm{I}-\mathrm{SP}\right)$, at a concentration of $0.1 \mathrm{nM}$, and concentrations of drug ranging from $0.0001-3 \mu \mathrm{M}$. For saturation studies, concentrations of ${ }^{125} \mathrm{I}-\mathrm{SP}$ ranging from 2 to $1000 \mathrm{pM}$ were incubated with membranes from each species. Non-specific binding for both assays was defined in the presence of $1 \mu \mathrm{M}$ of the NK1 antagonist, CP-99,994. All assays were terminated by rapid filtration, using a Tomtec cell harvester, onto GF/C filter plates that had been presoaked in $0.5 \%$ polyethylenamine. The plates were then dried and the bound radioactivity quantified using a Topcount scintillation counter (Packard Instruments, Meriden, CT, USA)

\section{Animals and Housing}

Female Mongolian gerbils (Meriones unguiculatus) (Charles River Laboratories, Kingston NY) weighing 30-50 g were used for all studies. On arrival at the holding facility, gerbils were housed three per cage, with food and water available ad-libitum, in a room maintained under constant temperature $\left(22 \pm 1^{\circ} \mathrm{C}\right)$ and humidity $(50 \%)$. Gerbils were maintained on a $12 \mathrm{~h}$ light/dark cycle (lights on 7:00 A.M.) and all behavioral testing was conducted during the light phase (between the hours of 10 A.M. and 4 P.M.). Gerbils were allowed one week to acclimate to the change in environment before any testing began, and testing occurred during all phases of the estrous cycle. All studies were carried out in accordance with the National Institute of Health 'Guide for the Care and Use of Laboratory Animals' and were conducted at AAALAC (Association for Assessment and Accreditation of Laboratory Animal Care)-accredited facilities under guidelines established by the ScheringPlough Animal Care and Use Committee.

\section{NK1 Agonist-induced Gerbil Foot-tapping}

To determine the potency of NK1 receptor antagonists to inhibit NK1 agonist-induced foot-tapping in gerbils, the pharmacodynamic assay described by Rupniak and Williams (1994) was used. Gerbils were anesthetized using an isoflurane/oxygen mixture and an incision was made to expose the skull surface. Once bregma was located, a 9-mm, 26-gauge needle was inserted through bregma to a depth of $5 \mathrm{~mm}$ (a $4 \mathrm{~mm}$ plastic sheath was placed over the shaft of the needle to ensure the correct depth). From previous histology studies, a depth of 5 $\mathrm{mm}$ was found to position the needle tip within the ventricles of the gerbil brain. Following insertion of the needle, 3 pmoles ( $5 \mu$ l dose volume) of the NK1 agonist GR-73632 was injected into the ventricles. The needle remained in the ventricle for approximately $30 \mathrm{~s}$ to al- low diffusion of the solution away from the site of injection. The incision was closed with two wound clips and a topical anesthetic (Xylocaine, Astra, Westborough, MA) was applied to the wound. The gerbil was then placed into a Plexiglas box and allowed to recover from the anesthesia. Immediately upon recovery of the righting reflex (approximately 1-2 $\mathrm{min}$ ), the amount of time spent foot-tapping during a $5 \mathrm{~min}$ observation period was recorded. For antagonism studies, NK1 receptor antagonists were administered orally (p.o.) $120 \mathrm{~min}$ before the i.c.v. injection of GR-73632. In a separate study, CP 99,994 was administered intraperitoneally (i.p.) 30 min prior to GR-73632 administration.

\section{Gerbil Elevated Plus-maze}

Testing was carried out on a specially-designed Plexiglas plus-maze with the floor of the maze constructed of black Plexiglas with $6.5 \mathrm{~mm}$ diameter holes incorporated into the floor, approximately $1 \mathrm{~cm}$ apart. Details of the apparatus, experimental procedure, and behavioral analysis are described in Varty et al. (2002).

\section{Drugs}

The NK1 receptor antagonists tested were MK-869 (0.01-3 mg/kg), L-742,694 (1-30 mg/kg), L-733,060 (1-10 $\mathrm{mg} / \mathrm{kg}$ ), CP-99,994 (3-30 mg/kg), and CP-122,721 (3-30 $\mathrm{mg} / \mathrm{kg}$ ). The NK1 agonist GR-73632, and the NK1 antagonist L-733,060 were purchased from RBI/Sigma (Natick, MA). MK-869, L-742,694, CP-99,994, and CP122,721 were synthesized by the Chemistry Research Department of the Schering-Plough Research Institute (Kenilworth, NJ). GR-73632 (approximately 97\% purity) was dissolved in distilled water to a stock concentration of $1 \mathrm{nmole} / \mu \mathrm{l}$. The stock was then diluted to a 0.6 pmole/ $\mu \mathrm{l}$ concentration and $100 \mu \mathrm{l}$ aliquots were stored at $-80^{\circ} \mathrm{C}$. The NK1 antagonists were administered via oral gavage (p.o.) or intraperitoneal (i.p.) administration in $0.4 \%$ methylcellulose at a volume of $5-10$ $\mathrm{ml} / \mathrm{kg}$ (depending on solubility), 30-120 min before testing. Doses and pretreatment times were determined using data from pharmacokinetic studies in rats, and NK1 agonist-induced foot-tapping studies in gerbils (see discussion and Bristow and Young 1994; Rupniak and Williams 1994).

\section{Data and Statistical Analysis}

For the in-vitro binding studies, the dissociation constant $(\mathrm{Kd})$ of ${ }^{125} \mathrm{I}-\mathrm{SP}$ in each species was determined by plotting the specific bound at each concentration of radioligand and performing non-linear regression analysis (GraphPad Prism, San Diego, CA). For competition studies, the $\mathrm{IC}_{50}$ for each drug to inhibit the binding of ${ }^{125} \mathrm{I}$-SP in each species was determined by plotting the 
specific bound at each concentration of drug, after which non-linear regression analysis was performed. Affinity constants (Ki) were then calculated using the equation derived by Cheng and Prusoff (1973), where $\mathrm{Ki}=\mathrm{IC}_{50} / 1+($ Conc(ligand $) / \mathrm{Kd}($ ligand $)$ ).

In the elevated plus-maze studies, arm time, arm entries, and stretch-attend postures were analyzed using one-way analyses of variance (GraphPad InStat, San Diego, CA) with drug treatment as the between-subjects factor. The head dips measure was analyzed using a Kruskal-Wallis non-parametric test. The accepted level of significance was $p<.05$, and where appropriate, post-hoc analyses were carried out using Dunnett's $t$-test. For comparison to the foot-tapping data, a minimum effective dose (MED) was defined as the lowest dose that produced a significant increase in percentage of open arm time, compared with vehicle control.

In the foot-tapping studies, the MED was defined as the dose that produced greater than $50 \%$ inhibition of the foot-tapping response in the vehicle control group.

\section{RESULTS}

\section{In-vitro NK1 Binding Studies}

Table 1 summarizes the in-vitro binding affinity of the five NK1 antagonists at cloned human NK1 receptors, and rat and gerbil NK1 receptors from striatal tissue. All five NK1 antagonists exhibited similar binding to human and gerbil NK1 receptors; however, the binding affinity of each antagonist was greatly reduced at the rat NK1 receptor, compared with gerbil and human.

\section{Effects of NK1 Receptor Antagonists on GR-73632-induced Foot-tapping}

Following oral administration, all five NK1 antagonists attenuated the foot-tapping behavior induced by i.c.v. injection of the NK1 agonist GR-73632 (see Table 2). MK-869 and L-742,694 were the most potent of the NK1 antagonists with greater than $50 \%$ inhibition at a dose of $0.3 \mathrm{mg} / \mathrm{kg}$. The MED doses for L-733,060 and CP-

Table 1. Binding Affinity of MK-869, L-742,694, L-733,060, CP-99,994, and CP-122,721 at Gerbil, Rat, and Human NK1 Receptors

\begin{tabular}{lccc}
\hline & \multicolumn{3}{c}{ NK1 Receptor Binding (Ki: $\mathbf{n M )}$} \\
\cline { 2 - 4 } NK1 Antagonist & Gerbil & Rat & Human \\
\hline MK-869 & 0.08 & 1.92 & 0.28 \\
L-742,694 & 0.06 & 19.34 & 0.13 \\
L-733,060 & 0.08 & 93.13 & 0.20 \\
CP-99,994 & 0.13 & 30.52 & 0.25 \\
CP-122,721 & 0.02 & 1.22 & 0.08 \\
\hline
\end{tabular}

122,721 were $3 \mathrm{mg} / \mathrm{kg}$ and $10 \mathrm{mg} / \mathrm{kg}$, respectively. CP99,994 had the lowest potency with significant inhibition at an oral dose of $30 \mathrm{mg} / \mathrm{kg}$. The reduced potency of CP-99,994 probably reflects the poor oral bioavailability of this compound, for when the compound was administered i.p., the MED dose of CP-99,994 decreased to $1 \mathrm{mg} / \mathrm{kg}$ (see Table 2).

\section{Effects of NK1 Receptor Antagonists in the Gerbil Elevated Plus-maze}

MK-869 was the most potent of the NK1 antagonists with significant increases in percentage of open arm time $\left(\mathrm{F}_{6,35}=10.4, p<.0001\right)$ at doses from $0.03-3 \mathrm{mg} / \mathrm{kg}$ (Figure 1). MK-869 also increased percentage of open arm entries $\left(0.3 \mathrm{mg} / \mathrm{kg} ; \mathrm{F}_{6,35}=4.8, p<.01\right.$, Figure 1$)$ and head dips $(0.3-3 \mathrm{mg} / \mathrm{kg} ; p<.0001$, Table 3$)$, and decreased stretch-attend postures $\left(0.03-3 \mathrm{mg} / \mathrm{kg} ; \mathrm{F}_{6,35}=\right.$ $7.9, p<.0001$, Table 3). There was no effect of MK-869 on closed arm or total arm entries.

L-742,694 increased percentage of time spent in the open arm at a dose of $10 \mathrm{mg} / \mathrm{kg}\left(\mathrm{F}_{4,25}=3.5, p<.05\right.$, Figure 1). L-742,694 increased the percentage of open arm entries $\left(\mathrm{F}_{4,25}=3.5, p<.05\right)$ at the $3 \mathrm{mg} / \mathrm{kg}$ dose, compared with the vehicle control (Figure 1). L-742,694 significantly reduced the number of stretch-attend postures $\left(\mathrm{F}_{4,25}=5.5, p<.01\right.$, Table 3$)$ at doses of $3-30 \mathrm{mg} /$ $\mathrm{kg}$, and there was a trend toward an increase in head dips $(p=.07)$. There was no effect of L-742,694 on closed or total arm entries.

L-733,060 increased percentage of time spent in the open arm $\left(\mathrm{F}_{3,20}=2.8, p<.05\right)$ at the $10 \mathrm{mg} / \mathrm{kg}$ dose, compared with vehicle (Figure 1). L-733,060 reduced stretch-attend postures $\left(\mathrm{F}_{3,20}=4.8, p<0.05\right)$ at the 3 and $10 \mathrm{mg} / \mathrm{kg}$ doses, and increased head dips at doses

Table 2. The Potency of NK1 Receptor Antagonists to Inhibit NK1 Agonist-induced Foot-tapping and Increase Percentage of Open Arm Time in the Elevated Plus-maze in Gerbils

\begin{tabular}{|c|c|c|}
\hline \multirow[b]{2}{*}{ NK1 Antagonist* } & \multicolumn{2}{|c|}{ Minimum Effective Dose (MED: $\mathrm{mg} / \mathrm{kg}$ ) } \\
\hline & $\begin{array}{c}\text { Gerbil Foot- } \\
\text { Tapping Assay }\end{array}$ & $\begin{array}{l}\text { Percentage of Open } \\
\text { Arm Time in Gerbil } \\
\text { Elevated Plus-Maze }^{2}\end{array}$ \\
\hline MK-869 & 0.3 & 0.03 \\
\hline L-742,694 & 0.3 & 10 \\
\hline $\mathrm{L}-733,060$ & 3 & 10 \\
\hline CP-122,721 & 10 & 30 \\
\hline CP-99,994 & 30 & $>30$ \\
\hline CP-99,994 (IP route) & 1 & 30 \\
\hline
\end{tabular}

${ }^{1} \mathrm{MED}$ calculated as the lowest dose that produced at least a $50 \%$ inhibition of NK agonist-induced foot tapping vs. vehicle group.

${ }^{2} \mathrm{MED}$ calculated as the lowest dose that produced a significant increase in percentage of open arm time from the vehicle group.

${ }^{*}$ Administered orally unless stated otherwise. 

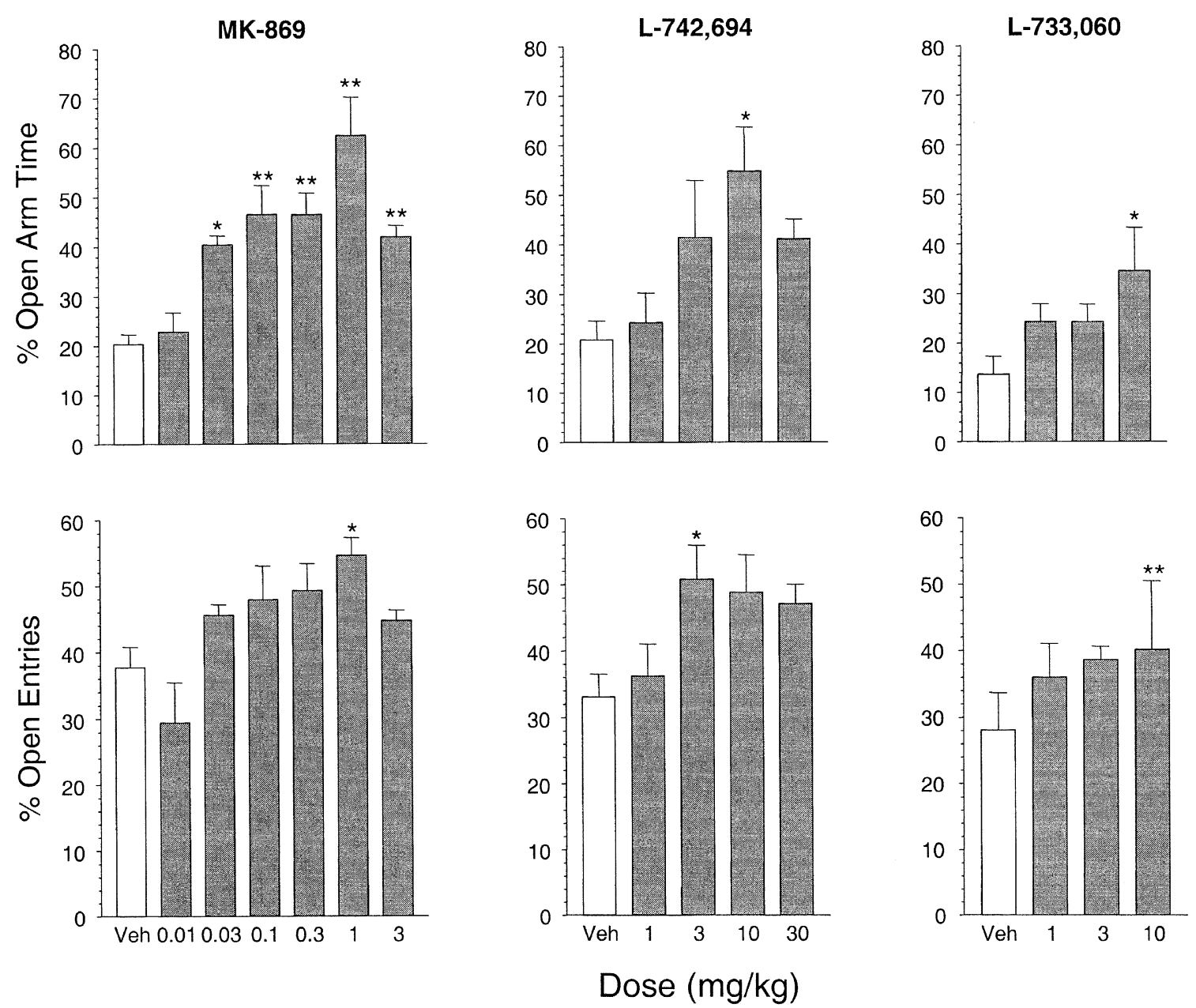

Figure 1. Effects of the NK1 antagonists MK-869 (0.01-3 mg/kg p.o.), L-742,694 (1-30 mg/kg p.o.), and L-733,060 (1-10 $\mathrm{mg} / \mathrm{kg}$ p.o.) on percentage of open arm time and percentage of open arm entries of the gerbil elevated plus-maze. $\mathrm{X}$-axes: Dose (mg/kg); Y-axes: percentage of Open Arm Time (upper panels), percentage of Open Arm Entries (lower panels). Values are mean \pm SEM. ${ }^{* *} p<.01,{ }^{*} p<.05$ vs. vehicle. $\mathrm{n}=6$ per dose group.

of 1 and $3 \mathrm{mg} / \mathrm{kg}(p<.01)$. There was no effect of L733,060 on open, closed, or total arm entries.

CP-99,994 had no effect on the percentage of open arm time, percentage of open arm entries, closed and total arm entries, or head dips (Figure 2 and Table 4). There was however, a significant effect of CP-99,994 to reduce the number of stretch-attend postures $\left(\mathrm{F}_{3,20}=\right.$ $4.5, p<.05)$ relative to vehicle, at doses of 3 and $30 \mathrm{mg} /$ $\mathrm{kg}$ (Table 4).

CP-122,721 increased percentage of open arm time $\left(\mathrm{F}_{3,20}=6.3, p<.01\right)$ at $30 \mathrm{mg} / \mathrm{kg}$ (Figure 2). There was no effect of CP-122,721 on open or closed arm entries, stretch-attend postures or head dips (Table 4).

Finally, the rank order of potency of the five NK1 antagonists in the gerbil foot-tapping assay was similar to the potency order in the gerbil elevated plus-maze (Table 2). With the exception of MK-869, NK1 antagonists were less potent in the gerbil elevated plus-maze.

\section{DISCUSSION}

The main aim of these studies was to test five selective NK1 receptor antagonists for anxiolytic-like activity using the elevated plus-maze, a traditional rodent model of anxiety recently adapted for the gerbil (see Varty et al. 2002).

We first confirmed, using in-vitro binding studies, that all five NK1 antagonists had comparable affinity for gerbil and human NK1 receptors, and reduced affinity for the rat NK1 receptor. These data corroborate previous findings that the majority of the selective NK1 antagonists have reduced affinity at rat and mouse NK1 receptors (Beresford et al. 1991; Gitter et al. 1991; McLean et al. 1993; Saria 1999). However, despite having a reduced affinity at the rat NK1 receptor compared with gerbil, two of the NK1 antagonists tested, namely MK-869 and CP-122,721, still exhibited 1-2 nM affinity 
Table 3. Effects of the NK1 Receptor Antagonists MK-869, L-742,694, and L-733,060 on Behavioral Measures from the Gerbil Elevated Plus-maze

\begin{tabular}{lcccccc}
\hline $\begin{array}{l}\text { Drug Dose } \\
\text { (mg/kg) }\end{array}$ & $\mathbf{n}$ & $\begin{array}{c}\text { Open Arm } \\
\text { Time }(\mathbf{s e c})\end{array}$ & $\begin{array}{c}\text { Closed Arm } \\
\text { Entries }\end{array}$ & $\begin{array}{c}\text { Total Arm } \\
\text { Entries }\end{array}$ & $\begin{array}{c}\text { Stretch-Attend } \\
\text { Postures }\end{array}$ & Head Dips \\
\hline MK-869 & & & & & & \\
Vehicle & 6 & $61 \pm 6$ & $20 \pm 2$ & $32 \pm 3$ & $27 \pm 2$ & $2 \pm 1$ \\
0.01 & 6 & $69 \pm 12$ & $24 \pm 2$ & $34 \pm 2$ & $20 \pm 2$ & $1 \pm 0.3$ \\
0.03 & 6 & $121 \pm 6^{*}$ & $23 \pm 2$ & $42 \pm 2$ & $11 \pm 2^{* *}$ & $8 \pm 1$ \\
0.1 & 6 & $140 \pm 17^{* *}$ & $17 \pm 3$ & $32 \pm 5$ & $7 \pm 3^{* *}$ & $11 \pm 2$ \\
0.3 & 6 & $139 \pm 13^{* *}$ & $22 \pm 1$ & $45 \pm 4$ & $14 \pm 3^{* *}$ & $13 \pm 2^{*}$ \\
1.0 & 6 & $187 \pm 24^{* *}$ & $14 \pm 3$ & $29 \pm 7$ & $7 \pm 2^{* *}$ & $22 \pm 4^{* *}$ \\
3.0 & 6 & $126 \pm 6^{* *}$ & $20 \pm 2$ & $36 \pm 3$ & $9 \pm 3^{* *}$ & $16 \pm 4^{*}$ \\
L-742,694 & & & & & & \\
Vehicle & 6 & $62 \pm 11$ & $18 \pm 3$ & $27 \pm 5$ & $15 \pm 3$ & $3 \pm 1$ \\
1.0 & 6 & $73 \pm 18$ & $20 \pm 4$ & $31 \pm 5$ & $13 \pm 2$ & $6 \pm 3$ \\
3.0 & 6 & $124 \pm 34$ & $14 \pm 3$ & $28 \pm 5$ & $7 \pm 2^{*}$ & $16 \pm 6$ \\
10.0 & 6 & $165 \pm 26^{*}$ & $16 \pm 4$ & $29 \pm 6$ & $5 \pm 2^{* *}$ & $13 \pm 3$ \\
30.0 & 6 & $123 \pm 12$ & $16 \pm 3$ & $30 \pm 5$ & $5 \pm 2^{* *}$ & $15 \pm 3$ \\
L-733,060 & & & & & \\
Vehicle & 6 & $41 \pm 11$ & $19 \pm 2$ & $27 \pm 4$ & $23 \pm 2$ & $0 \pm 0$ \\
1.0 & 6 & $73 \pm 11$ & $18 \pm 2$ & $28 \pm 2$ & $16 \pm 2$ & $2 \pm 2^{*}$ \\
3.0 & 6 & $73 \pm 11$ & $16 \pm 2$ & $26 \pm 2$ & $12 \pm 3^{*}$ & $0.5 \pm 0.3^{*}$ \\
10.0 & 6 & $104 \pm 26^{*}$ & $18 \pm 4$ & $27 \pm 4$ & $10 \pm 3^{* *}$ & $3 \pm 3$ \\
\hline
\end{tabular}

Values are mean \pm SEM

${ }^{*} p<.05$.

$* * p<.01$ vs. vehicle.

for the rat NK1 receptor. This data suggests that MK869 and $\mathrm{CP}-122,721$ may be suitable for testing in traditional rat models of anxiety and depression. Further studies are warranted to test this hypothesis, as the main aim of these studies was to compare five NK1 antagonists in the gerbil, a species in which the NK1 antagonists had equivalent NK1 receptor affinity.

Following in-vitro testing, the NK1 antagonists were tested in the NK1 agonist-induced foot-tapping assay, used routinely to measure the ability of NK1 antagonists to cross the blood-brain barrier, bind to the gerbil NK1 receptor, and block the central actions of a NK1 agonist (Bristow and Young 1994; Rupniak and Williams 1994; Rupniak et al. 1997). The five NK1 antagonists attenuated NK1 agonist-induced foot-tapping, albeit with differing potencies, confirming that these NK1 antagonists had oral bioavailability and brain penetration.

In the gerbil elevated plus-maze, all five NK1 antagonists produced anxiolytic-like effects following oral administration. The finding that these NK1 antagonists were able to modify elevated plus-maze behavior confirms that these compounds have oral bioavailability, and the ability to cross the blood-brain barrier and bind to gerbil NK1 receptors. Of the five NK1 antagonists, MK-869 was the most potent in the elevated plus-maze, with anxiolytic-like effects at doses as low as $0.03 \mathrm{mg} /$ $\mathrm{kg}$. Additionally, MK-869 reduced stretch-attend postures, and increased head dips and open arm entries, further indications of anxiolytic-like activity. This anxi- olytic-like profile for MK-869 was similar to the effects of the benzodiazepine, diazepam (see Varty et al. 2002). Both MK-869 and diazepam produced approximately $40 \%$ increases in open arm time, as well as significant increases in open arm entries and head dips, and decreases in stretch-attend postures. Thus, it appears that blockade of the NK1 receptor can mimic the anxiolyticlike efficacy observed by the benzodiazepine, diazepam, on both the open arm and ethological measures. Furthermore, comparing the effects of MK-869 to the published effects of antidepressant drugs in the gerbil elevated plus-maze (Varty et al. 2002), MK-869 produced a broader range of effects, compared with the antidepressants, which were limited to either effects on open arm time (fluoxetine and paroxetine) or stretchattend postures (imipramine).

L-742,694 and L-733,060 had very similar profiles, while CP-122,721 was the least potent of the NK1 antagonists with an increase in open arm time at the highest dose $(30 \mathrm{mg} / \mathrm{kg}$ ) being the only measurable anxiolyticlike response. These anxiolytic effects were not due to changes in locomotor activity as MK-869, L-742,694, L-733,060 and CP-122,721 did not affect closed or total arm entries. CP-99,994 was the only compound that did not demonstrate anxiolytic-like activity on the percentage of open arm time measure following oral administration, although an anxiolytic-like effect on stretchattend postures was observed. The reduced anxiolyticlike effects with CP-99,994 (and possibly CP-122,721, as it is structurally related to $\mathrm{CP}-99,994)$ may be due to 

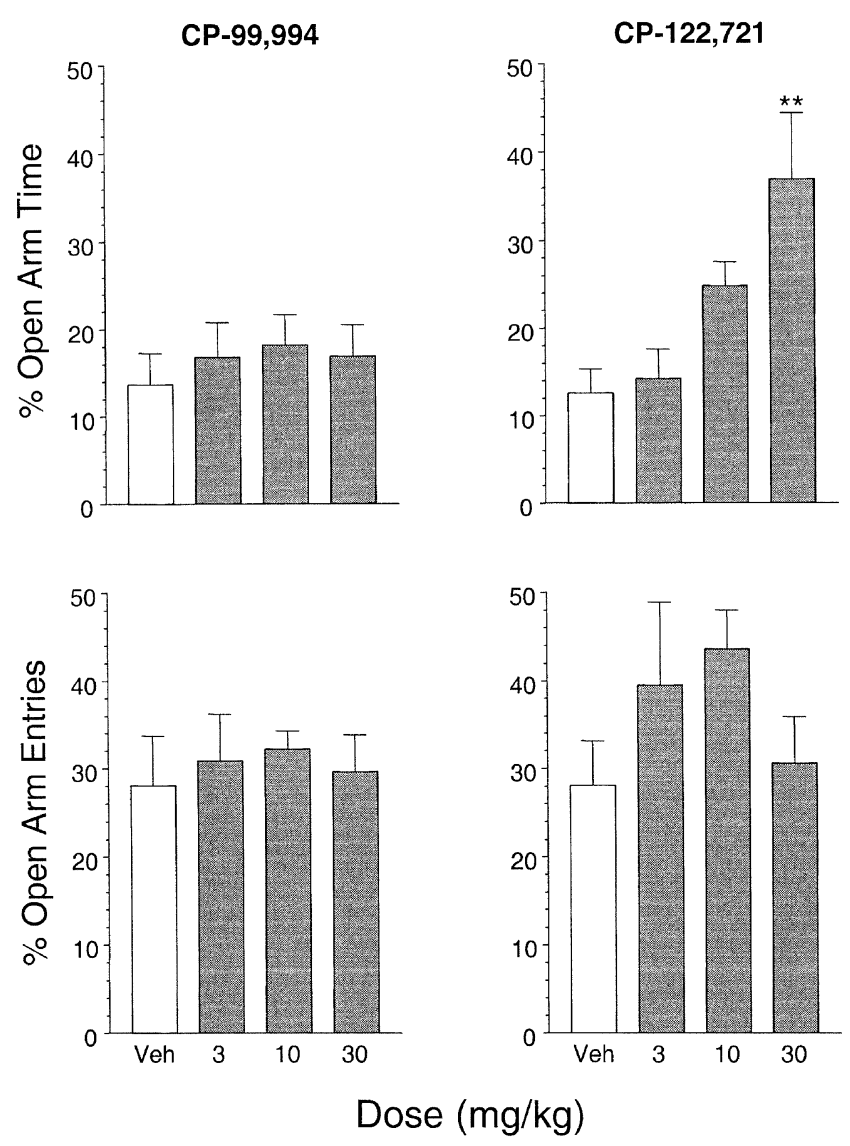

Figure 2. Effects of the NK1 antagonists CP-99,994 (3-30 mg/ $\mathrm{kg}$ p.o.) and CP-122,721 (3-30 mg/kg p.o.) on percentage of open arm time and percentage of open arm entries of the gerbil elevated plus-maze. X-axes: Dose (mg/kg); Y-axes: percentage of Open Arm Time (upper panels), percentage of Open Arm Entries (lower panels). Values are mean \pm SEM. ${ }^{* *} p<.01$, vs. vehicle. $n=6$ per dose group.

low oral bioavailability. CP-99,994 potently blocked NK1 agonist-induced foot-tapping when administered i.p. at a dose of $1 \mathrm{mg} / \mathrm{kg}$, but was only active orally at a
$30 \mathrm{mg} / \mathrm{kg}$ dose (see Table 2). Similarly, when CP-99,994 was administered i.p. to gerbils tested on the elevated plus-maze, there was a significant increase in percentage of open arm time at a $30 \mathrm{mg} / \mathrm{kg}$ dose (Table 2), an effect that was not observed following oral administration.

The rank order of potency of the NK1 antagonists to produce an anxiolytic-like increase in open arm time $(\mathrm{MK}-869>\mathrm{L}-742,694=\mathrm{L}-733,060>\mathrm{CP}-122,721>\mathrm{CP}-$ $99,994)$ on the elevated plus-maze was almost identical to the order of potency of these drugs to reduce NK1 agonist-induced foot-tapping (MK-869 $=$ L-742,694 > L-733,060 > CP-122,721 > CP-99,994). Since the gerbil NK1 receptor binding values were similar for all five compounds, differences in pharmacokinetics and brain penetration most likely account for the rank order. The rank order finding suggests that the gerbil foot-tapping assay may predict the potency of compounds in the gerbil elevated plus-maze assay, and vice versa. To confirm this, a correlation analysis of the potencies of NK1 antagonists in the two assays should be performed when further selective NK1 receptor antagonists are available for testing.

Interestingly, with the exception of MK-869, the NK1 antagonists were less potent in the gerbil elevated plusmaze than the foot-tapping assay. It is difficult to speculate on the reason for the lower potency, but it may simply reflect the different nature of the tests. The foottapping assay uses a pharmacologically driven behavior that is stimulated directly by a selective neurokinin NK1 agonist. The gerbil elevated plus-maze exploits an animal's fear of open, aversive environments in the absence of any agonist challenge. Another possible explanation may be that the i.c.v. injection procedure utilized in the foot-tapping assay compromises the permeability of the blood-brain barrier. While this may not alter the potency of the NK1 antagonists that have good bloodbrain barrier permeability, it may increase the penetration of those NK1 antagonists that normally would not

Table 4. Effects of the NK1 Receptor Antagonists CP-99,994 and CP-122,721 on Behavioral Measures from the Gerbil Elevated Plus-maze

\begin{tabular}{lcccccc}
\hline $\begin{array}{l}\text { Drug Dose } \\
(\mathbf{m g} / \mathbf{k g})\end{array}$ & $\mathbf{n}$ & $\begin{array}{c}\text { Open Arm } \\
\text { Time }(\mathbf{s e c})\end{array}$ & $\begin{array}{c}\text { Closed Arm } \\
\text { Entries }\end{array}$ & $\begin{array}{c}\text { Total Arm } \\
\text { Entries }\end{array}$ & $\begin{array}{c}\text { Stretch-Attend } \\
\text { Postures }\end{array}$ & Head Dips \\
\hline CP-99,994 & & & & & & \\
$\quad$ Vehicle & 6 & $41 \pm 11$ & $20 \pm 2$ & $28 \pm 4$ & $23 \pm 2$ & $0 \pm 0$ \\
3.0 & 6 & $51 \pm 12$ & $19 \pm 2$ & $29 \pm 4$ & $10 \pm 2^{* *}$ & $0 \pm 0$ \\
10.0 & 6 & $55 \pm 11$ & $19 \pm 2$ & $28 \pm 2$ & $16 \pm 3$ & $0.3 \pm 0.3$ \\
30.0 & 6 & $51 \pm 11$ & $20 \pm 2$ & $28 \pm 2$ & $14 \pm 3^{*}$ & $1.5 \pm 0.8$ \\
CP-122,721 & & & & & & \\
Vehicle & 6 & $38 \pm 8$ & $17 \pm 3$ & $23 \pm 4$ & $13 \pm 5$ & $0.2 \pm 0.2$ \\
3.0 & 6 & $43 \pm 10$ & $20 \pm 4$ & $34 \pm 7$ & $19 \pm 6$ & $0.2 \pm 0.2$ \\
10.0 & 6 & $75 \pm 8$ & $16 \pm 3$ & $28 \pm 5$ & $14 \pm 4$ & $0.5 \pm 0.3$ \\
30.0 & 6 & $111 \pm 22^{* *}$ & $21 \pm 3$ & $31 \pm 5$ & $8 \pm 6$ & $2.2 \pm 1.1$ \\
\hline
\end{tabular}

Values are mean \pm SEM

$* p<.05$.

${ }^{* *} p<.01$ vs. vehicle. 
permeate an intact blood-brain barrier to the same degree. This increased diffusion of the less penetrant NK1 antagonists into the gerbil CNS may account for the reduction in the minimum effective dose in foot-tapping, compared with elevated plus-maze activity. Further studies examining the effect of compromising the blood-brain barrier on the effects of drugs on behavior are needed to test this hypothesis.

In summary, all five selective NK1 antagonists produced anxiolytic-like effects in the gerbil elevated plusmaze, effects similar to the benzodiazepine anxiolytic drugs (see Varty et al. 2002). These findings corroborate the anxiolytic-like activity of NK1 antagonists in preclinical models that have been reported previously in mouse and rat elevated plus-mazes (Teixeira et al. 1996; Nikolaus et al. 1999), the guinea pig pup vocalization assay (Kramer et al. 1998), and the gerbil shock-induced foot-tapping assay (Ballard et al. 2001). Given the recent encouraging data from the clinical trials with MK-869 (Kramer et al. 1998), these findings further support the anxiolytic potential of selective NK1 receptor antagonists and suggest that the gerbil elevated plus-maze may be appropriate animal model for predicting clinical anxiolytic efficacy.

\section{ACKNOWLEDGMENTS}

The authors gratefully acknowledge Dr. John Hunter for editorial comments.

\section{REFERENCES}

Ballard TM, Sanger S, Higgins GA (2001): Inhibition of shock-induced foot tapping behaviour in the gerbil by a tachykinin NK(1) receptor antagonist. Eur J Pharmacol 412:255-264

Beresford IJ, Birch PJ, Hagan RM, Ireland SJ (1991): Investigation into species variants in tachykinin NK1 receptors by use of the non-peptide antagonist, CP-96,345. Br J Pharmacol 104:292-293

Bristow LJ, Young L (1994): Chromodacryorrhea and repetitive hind paw tapping: models of peripheral and central tachykinin NK1 receptor activation in gerbils. Eur J Pharmacol 253:245-252

Cascieri MA, Chicchi GG, Ling TM (1985): Demonstration of two distinct tachykinin receptors in rat brain cortex. J Biol Chem 260:1501-1507

Cheeta S, Tucci S, Sandhu J, Williams AR, Rupniak NMJ, File SE (2001): Anxiolytic actions of the Substance P $\left(\mathrm{NK}_{1}\right)$ receptor antagonist $\mathrm{L}-760,735$ and the $5-\mathrm{HT}_{1 \mathrm{~A}}$ agonist, 8-OH-DPAT in the social interaction test in gerbils. Brain Res 915:170-175

Cheng Y, Prusoff WH (1973): Relationship between the inhibition constant $(\mathrm{Ki})$ and the concentration of the inhibitor which causes 50 per cent inhibition $\left(\mathrm{I}_{50}\right)$ of the enzymatic reaction. Biochem Pharmacol 22:3099-3108
File SE (2000): NKP608, an NK1 receptor antagonist, has an anxiolytic action in the social interaction test in rats. Psychopharmacology (Berl) 152:105-109

File SE, Cheeta S, Akanezi C (2001): Diazepam and nicotine increase social interaction in gerbils: a test for anxiolytic action. Brain Res 888:311-313

Gitter BD, Waters DC, Bruns RF, Mason NR, Nixon JA, Howbert JJ (1991): Species differences in affinities of non-peptide antagonists for substance P receptors. Eur J Pharmacol 197:237-238

Hagan RM, Ireland SJ, Jordan CC, Beresford IJ, Deal MJ, Ward P (1991): Receptor-selective, peptidase-resistant agonists at neurokinin NK-1 and NK-2 receptors: New tools for investigating neurokinin function. Neuropeptides 19:127-135

Kramer MS, Cutler N, Feighner J, Shrivastava R, Carman J, Sramek JJ, Reines SA, Liu G, Snovely D, Wyatt-Knowles E, Hale JJ, Mills SG, MacCoss M, Swain CJ, Harrison T, Hill RG, Hefti F, Scolnick EM, Cascieri MA, Chicchi GG, Sadowski S, Williams AR, Hewson L, Smith D, Rupniak NMJ (1998): Distinct mechanism for antidepressant activity by blockade of central substance $P$ receptors. Science 281:1640-1645

McLean S, Ganong A, Seymour PA, Snider RM, Desai MC, Rosen T, Bryce DK, Longo KP, Reynolds LS, Robinson G, Schmidt AW, Siok C, Heym J (1993): Pharmacology of CP-99,994; a nonpeptide antagonist of the tachykinin neurokinin-1 receptor. J Pharmacol Exp Ther 267: $472-479$

McLean S, Ganong A, Seymour PA, Bryce DK, Crawford RT, Morrone J, Reynolds LS, Schmidt AW, Zorn S, Watson J, Fossa A, DePasquale M, Rosen T, Nagahisa A, Tsuchiya M, Heym J (1996): Characterization of CP-122,721; a nonpeptide antagonist of the tachykinin NK1 receptor. J Pharmacol Exp Ther 277:900-908

Molewijk HE, Hartog K, van der Poel AM, Mos J, Olivier B (1996): Reduction of guinea pig pup isolation calls by anxiolytic and antidepressant drugs. Psychopharmacology (Berl) 128:31-38

Nikolaus S, Huston JP, Hasenohrl RU (1999): The neurokinin-1 receptor antagonist WIN51,708 attenuates the anxiolytic-like effects of ventralpallidal substance $P$ injection. Neuroreport 10:2293-2296

Papp M, Vassout A, Gentsch C (2000): The NK1-receptor antagonist NKP608 has an antidepressant-like effect in the chronic mild stress model of depression in rats. Behav Brain Res 115:19-23

Pradier L, Habert-Ortoli E, Emile L, Le Guern J, Loquet I, Bock MD, Clot J, Mercken L, Fardin V, Garret C, Mayaux J-F (1995): Molecular determinants of the species selectivity of neurokinin type 1 receptor antagonists. Mol Pharmacol 47:314-321

Rupniak NM, Tattersall FD, Williams AR, Rycroft W, Carlson EJ, Cascieri MA, Sadowski S, Ber E, Hale JJ, Mills SG, MacCoss M, Seward E, Huscroft I, Owen S, Swain CJ, Hill RG, Hargreaves RJ (1997): In vitro and in vivo predictors of the anti-emetic activity of tachykinin NK1 receptor antagonists. Eur J Pharmacol 326:201-209

Rupniak NM, Williams AR (1994): Differential inhibition of foot tapping and chromodacryorrhoea in gerbils by CNS penetrant and non-penetrant tachykinin NK1 receptor antagonists. Eur J Pharmacol 265:179-183 
Saria A (1999): The tachykinin NK1 receptor in the brain: pharmacology and putative functions. Eur J Pharmacol 375:51-60

Teixeira RM, Santos AR, Ribeiro SJ, Calixto JB, Rae GA, De Lima TC (1996): Effects of central administration of tachykinin receptor agonists and antagonists on plusmaze behavior in mice. Eur J Pharmacol 311:7-14

Varty GB, Morgan CA, Cohen-Williams ME, Coffin VL,
Carey GJ (2002): The Gerbil Elevated Plus-Maze I: Behavioral characterization and pharmacological validation. Neuropsychopharmacology 27:357-370

Vassout A, Veenstra S, Hauser K, Ofner S, Brugger F, Schilling W, Gentsch C (2000): NKP608: a selective NK-1 receptor antagonist with anxiolytic-like effects in the social interaction and social exploration test in rats. Regul Pept 96:7-16 